\title{
NONLINEAR DYNAMIC ANALYSIS OF A CABLE UNDER FIRST AND SECOND ORDER PARAMETRIC EXCITATIONS
}

\author{
Mohamed Hechmi El Ouni ${ }^{1}$, Nabil Ben Kahla ${ }^{2}$ \\ ${ }^{1}$ Laboratory of Systems and Applied Mechanics, Polytechnic School of Tunisia, \\ University of Carthage, La Marsa, Tunisia \\ ${ }^{2}$ Department of Mechanical Engineering, Higher Institute of Applied Sciences and Technology of Sousse, \\ University of Sousse, Tunisia \\ E-mails: ${ }^{1}$ m.h.elouni@hotmail.com (corresponding author); ${ }^{2}$ Nabil.BenKahla@enig.rnu.tn
}

Received 27 Sept. 2010; accepted 18 Apr. 2011

\begin{abstract}
It is well known that small periodic vibrations of a cable support through its axial direction produce large spectacular oscillations of the cable. This may occur when the frequency of the anchorage motion is close to the first natural frequency or twice the fundamental frequency of the cable. In this paper, a nonlinear dynamic study of a cable under first and second order parametric excitations is presented. The cable model takes into account sag as well as quadratic and cubic nonlinear couplings between in-plane and out-of-plane motions. As a numerical example, a single-d.o.f. planar model of a horizontal cable is used to study the effect of frequency and amplitude of excitation as well as the natural damping of the cable on its transient and steady state responses with a particular focus on the time needed to trigger first and second order parametric resonance.
\end{abstract}

Keywords: small sagged cables, nonlinear vibration, parametric excitation, general support movement.

\section{Introduction}

Cables have been widely used in many engineering applications such as guyed towers, suspended bridges, cable stayed bridges, stadium roofs, etc. These structures are very flexible and sensitive to traffic, wind and seismic excitations. Thus, stay cables are prone to vibrate locally both in-plane and out-of-plane. Furthermore, cable vibrations can be accompanied by support motion. The coupling between the local (cable) and the global modes (structure) may give rise to parametric excitations (Sun et al. 2003). In fact, when a tuning process converges to certain conditions, even small periodic vibrations of the cable support through its axial direction produce large spectacular oscillations of the cable. This may occur when the frequency of the anchorage motion is close to the first natural frequency or twice the fundamental frequency of the cable (Lilien, Pinto da Costa 1994).

Cable dynamics bibliography is very rich. Classical linear modelling was addressed by Irvine (1992) in a book, Triantafyllou $(1984,1987,1991)$ and Starossek $(1994)$ in some review articles. As for nonlinear dynamics, modeling and analysis were highlighted in some review articles by Rega (2004a, b) and Ibrahim (2004). A small part of the extremely rich literature is cited here. Linear free and forced oscillations of elastic cables with a small sag-to-chord-length ratio based on the parabolic equilibrium approximation were first developed by Irvine (1992) and Irvine and Caughey (1974). Based on a single-degree-of-freedom model for the in-plane vibrations of the cable, Hagedorn and Schäfer (1980) extended the linear theory by considering the effect of quadratic and cubic non-linearities on eigen frequencies. These nonlinear terms come up due to the stretching of the cable associated with the large-amplitude vibration (Takahashi, Konishi 1987). The existence of the quadratic and cubic non-linear terms makes the in-plane cable motion couples with the out-of-plane cable motion and induces modal interaction (Perkins 1992). To determine the nonlinear dynamic response of a sag cable, the Galerkin method is often used to convert non-linear partial differential equations of motion to non-linear ordinary differential equations with respect to time functions only. Then, either the perturbation method (Benedettini et al. 1995; Chen, Xu 2009), or the harmonic balance method (Takahashi 1991) is applied to find the solution for the time functions. Nayfeh et al. (1995) investigated the nonlinear differential equations that govern the in-plane motion of a taut string under parametric excitation. They predicted the steady state response using the method of multiple scales. Ben Kahla (1995) presented a numerical model, of a single cable with large oscillations, based on a step by step integration method coupled with an iterative procedure. Juozapaitis and Norkus (2004) derived the expressions of maximum vertical and horizontal displacements of a asymmetrically loaded cable. Wu et al. (2005) did a modification in the expressions for the in-plane natural frequencies of an inclined cable as derived before by Irvine (1992). Ren et al. (2005) proposed empirical formulas to estimate cable tension based on the cable fundamental 
frequency only and validated them by comparing the results with those reported in the literature and with the experimental results carried out on a stay cable mock-up. Wu et al. (2003) examined local parametric vibrations in the stay cables of an existing cable-stayed bridge under sinusoidal excitations, traffic loadings and earthquake. Srinil and Rega (2007) studied the effects of kinematic condensation on internally resonant forced vibrations of shallow horizontal cables. Rega et al. (2008) carried experimental studies on free and parametrically-forced vibrations of sagged inclined cables and discussed them against theoretical and numerical analyses. Hu and Frank Pai (2010) conducted an experimental study of the nonlinear dynamic characteristics of taut cables using an extraordinary 3D motion analysis system. The planar and nonplanar/whirling vibration, hardening effect, and modal coupling vibration were successfully recorded and the hysteretic phenomenon of response was also observed. Wang and Zhao (2009a, b) applied the shooting method and the continuation technique to investigate the large amplitude motion and non-planar motion characteristic of an inclined cable subjected to support motion. Recently, Nielsen and Sichani (2011) analyzed the stochastic response and chaotic behaviour of a shallow cable by two comparable stochastic models of the chord elongation for the sub- and the superharmonic resonances.

Wang and Rega (2010) developed 3D nonlinear equations of motion of a suspended cable with moving mass and studied the effects of the inertia force, mass, sag and velocity of the moving mass on the transient dynamics of the cable. Takahashi and Chen (2006) studied the effect of cable loosening on the nonlinear parametric vibrations of inclined cables with small sag using a new technique that takes into account flexural rigidity and damping. An investigation on accurate finite element modelling of largediameter sagged cables taking into account flexural rigidity and sag extensibility is carried out by Ni et al. (2002). Lacarbonara and Pacitti (2008) presented a geometrically exact formulation of cables suffering axis stretching and flexural curvature based on nonlinearly visco-elastic constitutive laws for the tension and bending moment with an additional constitutive nonlinearity accounting for the nocompression condition. Treyssède (2010) studied the effect of thermal change on the frequencies of a cable taking into account flexural rigidity and sag. Sousa et al. (2011) analyzed the influence of bending and shear stiffness and rotational inertia in the natural frequencies of overhead transmission line conductors and compared the results with a vibrating string where only geometrical stiffness is considered. As the flexural rigidity has an effect on the natural frequencies in the case of suspended cables with large diameters, it can be neglected in the case of stay cables with smaller diameter. In this paper, we present a cable model which takes into account sag as well as quadratic and cubic nonlinear couplings between in-plane and outof-plane motions and movable support. The motivation of the use of a model accounting for general support movement is that it can simply be coupled with a finite element model of a cable stayed bridge which will be used to study the instabilities of stay cables under parametric excitation and active control of vibrations. The objective of the present study is to analyze the nonlinear dynamic behaviour of a cable under first and second order (i.e., principal and fundamental) parametric excitations with a comparative construction of frequency, force and damping-response diagrams for the two cases of parametric excitation with a particular focus on the time needed to trigger the two resonances.

The paper is organized as follow: in section 2, a nonlinear model of a cable with small sag and movable support is presented. In section 3, a numerical example of a singled.o.f. planar model of a horizontal cable is used to study the effect of frequency and amplitude of excitation as well as the natural damping of the cable on its transient and steady state responses with a particular focus on the time needed to trigger first and second order parametric resonance. The paper ends with some conclusions.

\section{Nonlinear modelling of an inclined cable with small sag}

The non-linear model of the inclined cable takes into account the sag effect, coupling between the in-plane and out-of-plane motions and also the displacements of the anchorage points. The model of the cable is written in a local coordinate system as indicated in Fig. 1; the local $x$ axis is taken along the string line and $y$ axis in the horizontal plane, while the $z$ axis is in the gravity plane and perpendicular to the chord line. The cable displacements can be separated into three parts: the static, the quasistatic and the dynamic contributions. A brief description of the nonlinear model of the cable is presented hereafter (for more details see Bossens 2001).

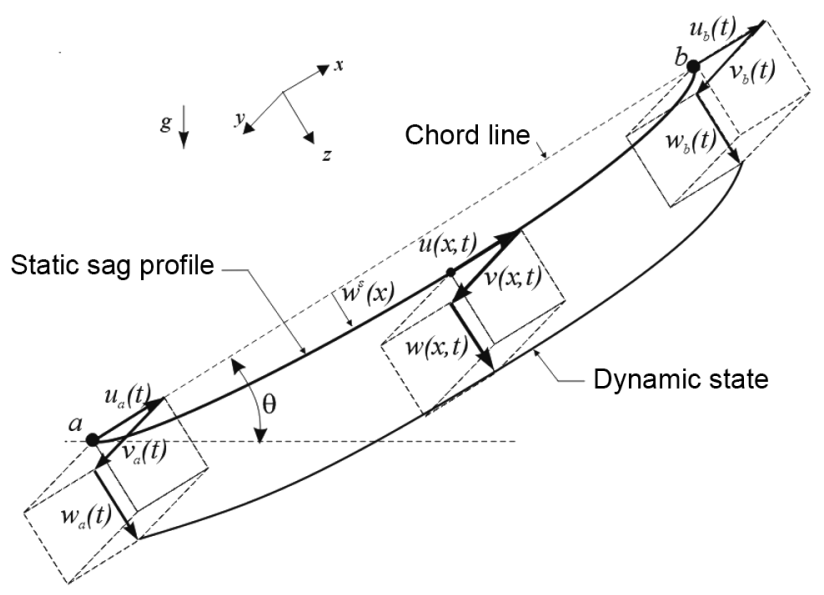

Fig. 1. 3D-model of an inclined cable with support motions

\subsection{Static configuration}

The static configuration of a cable is a function of its weight and pre-stress when the anchorage points are fixed in the initial position. Assuming small sag and a constant stress along the cable span, the static profile of an inclined cable can be approximated by a parabola. The static sag of a given point of coordinate $x$ along the cable chord is given by the following relation:

$$
w^{s}(x)=\frac{\gamma l^{2}}{2 \sigma^{s}}\left[\frac{x}{l}-\left(\frac{x}{l}\right)^{2}\right]
$$


where: $\sigma^{s}$ is the static stress; $l$ the length of the cable's chord; $\gamma$ is the component of weight density along $z$ axis which is equal to $\rho g \cos \theta$. With $\rho$ the cable mass density, $g$ the gravity and $\theta$ the angle of the chord line with respect to the horizontal.

\subsection{Quasi static motion}

The quasi-static motion due to the support movements of anchorage points $a$ and $b$ can be written as:

$$
\begin{gathered}
u^{q}(x, t)=u_{a}-\frac{w_{b}-w_{a}}{l} w^{s}(x)+\left(u_{b}-u_{a}\right) \frac{x}{l} ; \\
v^{q}(x, t)=v_{a}+\left(v_{b}-v_{a}\right) \frac{x}{l} ; \\
w^{q}(x, t)=w_{a}+\left(w_{b}-w_{a}\right) \frac{x}{l}-\frac{E_{q}}{\sigma^{s}} \frac{u_{b}-u_{a}}{l} w^{s}(x),
\end{gathered}
$$

where: $E_{q}$ is the effective modulus of elasticity (see Appendix); $u_{a}, u_{b}, v_{a}, v_{b}, w_{a}$ and $w_{b}$ are the movements imposed to anchorage points.

\subsection{Dynamic motion}

The dynamic motion of the cable subjected to the excitation of its supports formulated in a discrete manner is obtained by employing the Ritz method. This method is based on approaching the solution of variational problem by a finite sum of shape functions. The "separation of variables" method is used to write the shape functions with two well separated factors (geometric and temporal).

For small sag, the axial dynamic component can be neglected and:

$$
\begin{gathered}
u^{d}(x, t) \approx 0 ; \\
v^{d}(x, t)=\sum_{n} y_{n}(t) \varphi_{n}(x)=\sum_{n} y_{n}(t) \sin \frac{n \pi x}{l} ; \\
w^{d}(x, t)=\sum_{n} z_{n}(t) \psi_{n}(x)=\sum_{n} z_{n}(t) \sin \frac{n \pi x}{l} .
\end{gathered}
$$

The global displacement of the cable is obtained from the superposition of the static displacement, quasistatic and dynamic motion as:

$$
\begin{gathered}
u(x, t)=u^{q}(x, t) ; \\
v(x, t)=v^{q}(x, t)+v^{d}(x, t) ; \\
w(x, t)=w^{s}(x)+w^{q}(x, t)+w^{d}(x, t) .
\end{gathered}
$$

The total displacement of the cable will be completely defined by the following coordinates:

$$
u_{a}, u_{b}, v_{a}, v_{b}, w_{a}, w_{b}, \ldots y_{i} \ldots, \ldots z_{i} .
$$

The kinetic energy of the cable is given by:

$$
K_{c}=\frac{1}{2} \rho A \int_{0}^{l}\left[\dot{u}^{2}+\dot{v}^{2}+\dot{w}^{2}\right] d x .
$$

The potential energy of the cable contains the contribution of the elastic elongation of the cable and the gravitational potential:

$$
\begin{gathered}
U_{c}=\frac{1}{2} E A \int_{0}^{l} \varepsilon(x, t)^{2} d x- \\
\rho g A \int_{0}^{l}\left[\left(w^{s}+w^{q}+w^{d}\right) \cos \theta-u^{q} \sin \theta\right] d x,
\end{gathered}
$$

where $E$ is the modulus of elasticity and $\varepsilon$ is the axial strain in the cable which is supposed to be the only contribution to the strain energy.

The axial strain is evaluated using Green's tensor of strain:

$$
\varepsilon_{i j}=\frac{1}{2}\left(\frac{\partial u_{i}}{\partial x_{j}}+\frac{\partial u_{j}}{\partial x_{i}}+\frac{\partial u_{k}}{\partial x_{i}} \frac{\partial u_{k}}{\partial x_{j}}\right) .
$$

The expressions of the Kinetic and potential energies are given in the Appendix.

\subsection{Equation of horizontal modes of the cable}

Substituting the expressions of the kinetic and potential energies in the Lagrange equations, we obtain the differential equations governing the generalized coordinates $y_{n}$ of the $n^{\text {th }}$ cable mode:

$$
\frac{d}{d t}\left(\frac{\partial K_{c}}{\partial \dot{y}_{n}}\right)+E A l \bar{\varepsilon} \frac{\partial(\bar{\varepsilon})}{\partial y_{n}}=F_{y_{n}},
$$

where $F_{y_{n}}$ is the modal component, associated to $y_{n}$, of the external forces applied to the cable.

Thus, by adding a damping term, the equations of motion become:

$$
\begin{gathered}
\frac{1}{2} m l\left\{\ddot{y}_{n}+2 \xi_{y n} \omega_{n} \dot{y}_{n}+\frac{n^{2} \pi^{2}}{m l^{2}}\left(T_{0}+T_{q}+T_{d}\right) y_{n}\right\}= \\
F_{y_{n}}-\frac{m l}{n \pi}\left(\ddot{v}_{a}+(-1)^{n+1} \ddot{v}_{b}\right),
\end{gathered}
$$

where $\xi_{y_{n}}, \omega_{y_{n}}$ and $F_{y_{n}}$ are respectively the modal damping, the frequency and the modal component of the external forces applied to the cable, associated to the generalized coordinates $y_{n}$ of the $n^{\text {th }}$ cable mode. The cable mass per unit length is $m, \ddot{v}_{a}$ and $\ddot{v}_{b}$ are respectively the transverse acceleration of the anchorage points $a$ and $b$ with respect to the $y$ axis, $T_{0}$ is the static tension in the cable at its equilibrium and $T_{q}=T_{q}^{(1)}+T_{q}^{(2)}$ is the tension increment induced by the support movement with:

$$
T_{q}^{(1)}=E_{q} A \frac{u_{b}-u_{a}}{l} ;
$$




$$
\begin{gathered}
T_{q}^{(2)}=E A \quad\left(1+\frac{E_{q}}{\sigma^{s}} \frac{\lambda^{2}}{12+\lambda^{2}}\right) \quad \frac{\left(u_{b}-u_{a}\right)^{2}}{2 l^{2}} ; \\
+E A \frac{\left(v_{b}-v_{a}\right)^{2}}{2 l^{2}}+E A\left(1+\frac{\lambda^{2} \sigma^{s}}{12 E}\right) \frac{\left(w_{b}-w_{a}\right)^{2}}{2 l^{2}},
\end{gathered}
$$

where: $A$ is the cable cross section area and $\lambda^{2}$ is the Irvine's parameter (Irvine 1992) (see Appendix), $T_{d}=T_{d}^{(1)}+T_{d}^{(2)}$ is the tension increment induced by the dynamic motion of the cable, which is responsible for the quadratic and cubic nonlinear couplings between in-plane and out-of-plane motion:

$$
\begin{gathered}
T_{d}^{(1)}=\frac{E A^{2} \gamma}{T_{0}} \sum_{n}\left[\frac{z_{n}}{n \pi}\left(1+(-1)^{n+1}\right)\right] \\
T_{d}^{(2)}=\frac{E A}{2} \sum_{n}\left(y_{n}^{2} \frac{n^{2} \pi^{2}}{2 l^{2}}\right)+\frac{E A}{2} \sum_{n}\left(z_{n}^{2} \frac{n^{2} \pi^{2}}{2 l^{2}}\right)- \\
\frac{E_{q} E A \quad \gamma}{\left(\sigma^{s}\right)^{2}} \frac{u_{b}-u_{a}}{l} \sum_{n}\left[\frac{z_{n}}{n \pi}\left(1+(-1)^{n+1}\right)\right]
\end{gathered}
$$

\subsection{Equation of transverse modes of the cable}

The equations of motion describing the transverse modes of vibration can be developed using the same strategy as for determining the equation governing the horizontal modes of vibration of an inclined cable with small sag:

$$
\frac{d}{d t}\left(\frac{\partial K_{c}}{\partial \dot{z}_{n}}\right)+E A l \bar{\varepsilon} \frac{\partial(\bar{\varepsilon})}{\partial z_{n}}+\frac{\partial\left(U_{c, g}\right)}{\partial z_{n}}=F_{z_{n}} .
$$

By assuming that $\frac{T_{q}^{2}}{T_{0}^{2}}<<1$ and $\frac{T_{d}}{T_{0}}<<1$ and limiting $T_{q}$ to the first order, one can write:

$$
\begin{gathered}
\frac{1}{2} m l\left\{\ddot{z}_{n}+2 \xi_{z_{n}} \omega_{n} \dot{z}_{n}+\frac{n^{2} \pi^{2}}{m l^{2}}\left(T_{0}+T_{q}+T_{d}\right) z_{n}\right\}=F_{z_{n}} \\
-\frac{m l}{n \pi}\left(\ddot{w}_{a}+(-1)^{n+1} \ddot{w}_{b}\right)+\frac{m l^{2} E_{q} \gamma}{\left(\sigma^{s}\right)^{2}} \frac{\left(1+(-1)^{n+1}\right)}{(n \pi)^{3}}\left(\ddot{u}_{b}-\ddot{u}_{a}\right)- \\
\frac{\gamma A l}{T_{0}} \frac{\left(1+(-1)^{n+1}\right)}{n \pi} T_{d},
\end{gathered}
$$

where: $\xi_{z_{n}}, \omega_{z_{n}}$ and $F_{z_{n}}$ are respectively the modal damping, the frequency and the modal component of the external forces applied to the cable, associated with the generalized coordinates $z_{n}$ of the $n^{\text {th }}$ cable mode. The inplane acceleration of the anchorage points $a$ and $b$ with respect to the $z$ axis are respectively $\ddot{w}_{a}$ and $\ddot{w}_{b}$, the longitudinal acceleration of the anchorage points $a$ and $b$ with respect to the $x$ axis are respectively $\ddot{u}_{a}$ and $\ddot{u}_{b}$.

This model had been implemented into a MATLAB/ SIMULINK program.

\section{Numerical example}

In this section, the dynamic response of a single-d.o.f. planar model of a horizontal cable $(a b)$ with small sag (nearly taut cable), fixed at its right end and attached to a roller support at its left end so that only horizontal motion is allowed at this node, had been studied under a first and a second order (i.e., principal and fundamental) parametric excitation. The $k^{\text {th }}$ order parametric excitation is obtained for a frequency of excitation $\omega_{k}=2 \omega_{0} / k(k=1,2,3, \ldots)$. The geometrical and physical properties of the stainless steel cable are given in Table 1. The cable is located before the first crossover of natural frequencies. In fact, the cable had been excited through its axial direction $\left(u_{a}\right)$ at its left end with a frequency close to its fundamental frequency then close twice that of its first natural frequency (see Fig. 2). The effect of frequency and amplitude of excitation as well as the natural damping of the cable on the steady state response had been investigated.

Table 1. Cable parameters

\begin{tabular}{l|c}
\hline \multicolumn{1}{c|}{ Parameters } & Values \\
\hline Length $l$ & $1.745 \mathrm{~m}$ \\
Diameter $\varphi$ & $1 \times 10^{-3} \mathrm{~m}$ \\
Modulus of elasticity $E$ & $105 \times 10^{9} \mathrm{~Pa}$ \\
Density & $6251 \mathrm{~kg} / \mathrm{m}^{3}$ \\
Lumped mass every $10 \mathrm{~cm}$ along the cable & $10 \mathrm{~g}$ \\
Initial static tension $T_{0}$ & $100 \mathrm{~N}$ \\
Sag $d / l$ & $0.195 \%$ \\
Irvine's parameter & 0.2 \\
Modal damping $\xi_{0}$ & $0.3 \%$ \\
\hline
\end{tabular}

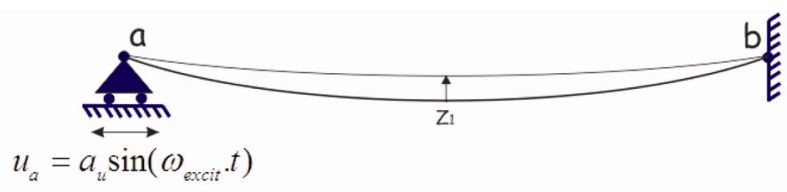

Fig. 2. Parametric excitation of a cable

\subsection{First order parametric excitation}

\subsubsection{Effect of the frequency of excitation}

The tension of the cable is tuned to $100 \mathrm{~N}$ which corresponds to a first natural frequency of the cable $\omega_{0}=$ $60.2 \mathrm{rad} / \mathrm{s}$ and excited harmonically $\left(u_{a}=a_{u} \sin \left(\omega_{\text {excit }} t\right)\right)$ through its axial direction by a frequency $\omega_{\text {excit }}=2 \omega_{0}$ and with an amplitude of excitation $a_{u}=0.1 \mathrm{~mm}$. The time evolution of the mid span vertical displacement (Z1) is plotted in Fig. 3a. This figure shows large spectacular vertical oscillations of the cable at mid span under first order parametric excitation. First the response of the cable is dominated by small oscillations with a period corresponding to a frequency of $2 \omega_{0}$ which characterises the antisymmetric mode of vibration of the cable. Next, a progressive change of the cable vibration frequency is established and converges to $\omega_{0}$ (Fig. 3b) the first natural frequency of the cable. Large oscillations of the cable characterising the symmetric mode of vibration are obtained. 


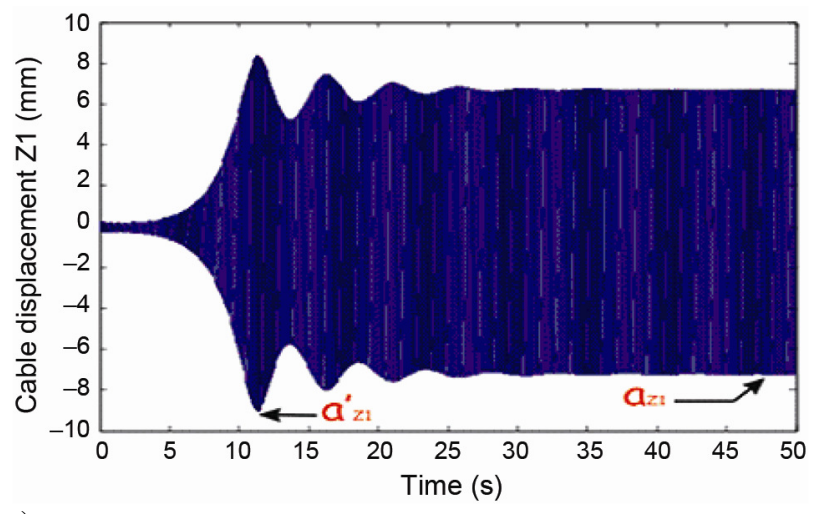

a)

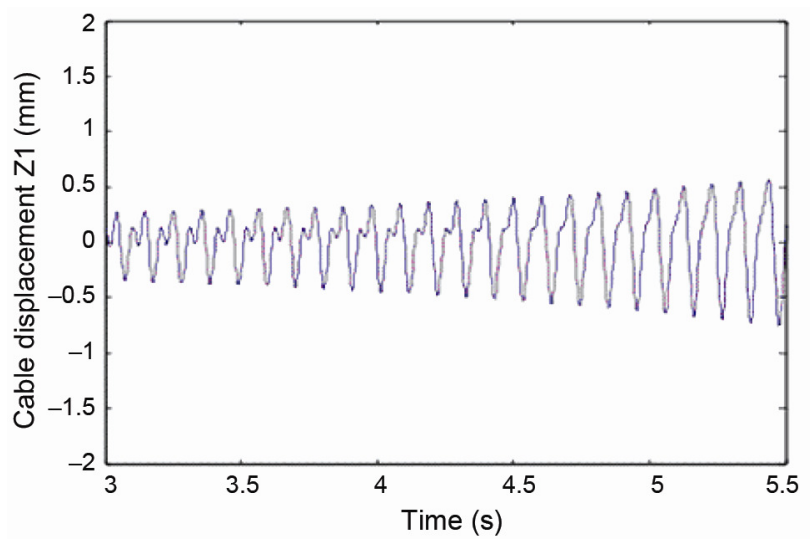

b)

Fig. 3. In-plane cable vibration at mid span under first order parametric excitation as a function of time (a); zoom between 3 $\mathrm{s}$ and $5.5 \mathrm{~s}(\mathrm{~b})$

Now, let's change the frequency of excitation near the initial frequency of excitation $\left(2 \omega_{0}\right)$. The maximum amplitude of both transient $\left(a^{\prime}{ }_{Z 1}\right)$ and steady state $\left(a_{Z 1}\right)$ in-plane response of the cable at mid span is plotted as a function of the frequency of excitation. Fig. $4 \mathrm{a}$ shows that the maximum in-plane displacement $\mathrm{Z} 1$ depends on a minimum $\left(\omega_{\min }\right)$ and maximum $\left(\omega_{\max }\right)$ threshold frequency of excitation (equal to 119.1 and $121.7 \mathrm{rad} / \mathrm{s}$ in this case) to be triggered. The in-plane displacement $\mathrm{Z1}$ increases as the frequency of excitation travels from $\omega_{\min }$ to $\omega_{\max }$ then jumps down. Otherwise, out of this interval the first order parametric resonance does not occur. The transient response disappears when the frequency is close to $\omega_{\min }$ and the difference between the maximum amplitude of both transient $a_{Z 1}^{\prime}$ and steady state $a_{Z 1}$ responses decreases when the frequency of excitation increases from $\omega_{\min }$ to $\omega_{\max }$. The shape of the frequency-response curve in Fig. 4a is qualitatively similar with the analogous curve obtained by Rega and Benedettini (1989) for the single d.o.f model of suspended cable using multiple scale method.

The necessary time to trigger parametric resonance is also plotted as a function of the frequency of excitation (Fig. 4b). Parametric resonance triggers faster when the frequency of excitation is close to $2 \omega_{0}$ but triggers slower when frequency is near $\omega_{\min }$ and $\omega_{\max }$.

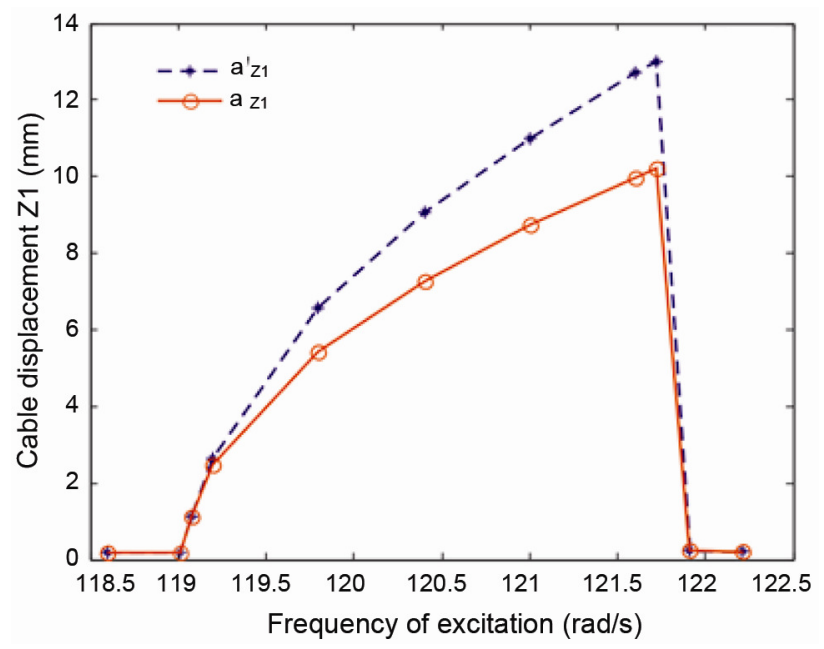

a)

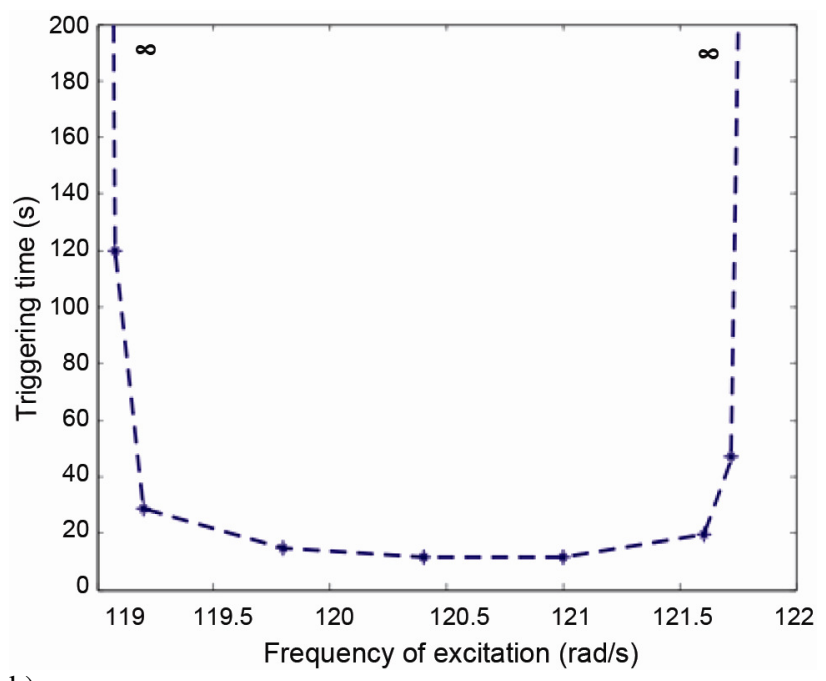

b)

Fig. 4. Maximum mid span cable displacement (a); necessary time to trigger first order parametric resonance as a function of the frequency of excitation (b)

\subsubsection{Effect of the amplitude of excitation}

Let's fix the frequency of the excitation at $\omega_{\text {excit }}=2 \omega_{0}$ and progressively change the amplitude of excitation. The transient and steady state response of the cable are plotted as a function of the amplitude of excitation $\left(a_{u}\right)$. Fig. 5a shows that the parametric resonance needs threshold amplitude of excitation to be triggered, as proved by Rega and Benedettini (1989), and that the maximum in-plane displacement $a_{Z 1}$ of the cable increases by increasing the amplitude of excitation. This means that in cable stayed bridges, first order parametric excitation could be prevented by damping the deck or the pylon and keeping their amplitudes of vibration under the threshold value needed to trigger parametric resonance. The difference between the maximum amplitude of both transient and steady state responses increases by increasing the amplitude of excitation.

Fig. 5b shows that the time needed to trigger a parametric resonance decreases by increasing the amplitude of excitation and goes to infinity when the amplitude of excitation is under the threshold value. 


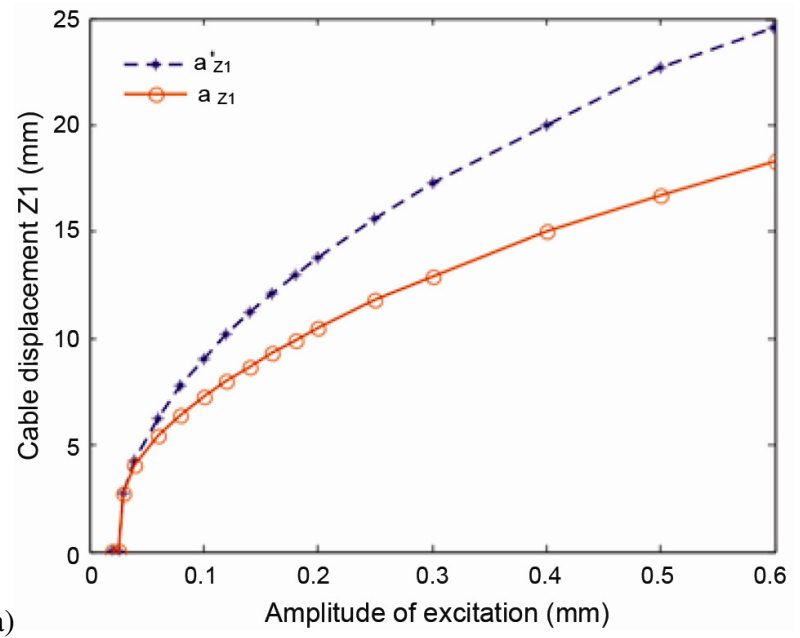

a)

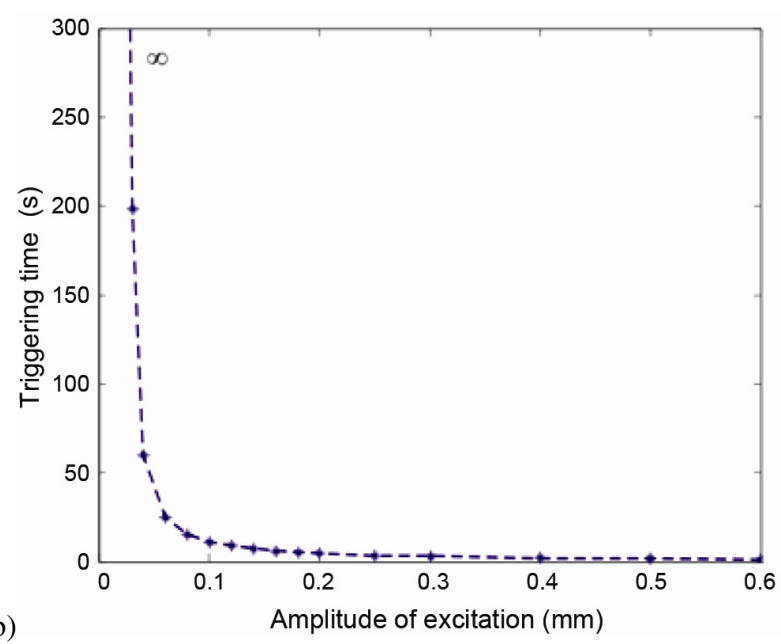

Fig. 5. Maximum mid span cable displacement (a); necessary time to trigger first order parametric resonance; as a function of the amplitude of excitation (b)

\subsubsection{Effect of the natural damping of the cable}

Next, the amplitude and the frequency of excitation are fixed respectively to $a_{u}=0.1 \mathrm{~mm}$ and $\omega_{\text {excit }}=2 \omega_{0}$. The natural damping $\left(\xi_{0}=0.3 \%\right.$ ) of the cable is changed from small to high values. For small values of natural damping, a beating phenomenon is obtained as could be seen in Fig. 6a and Fig. 6d. A progressive change of the frequency of the cable from $2 \omega_{0}$ to $\omega_{0}$, then from $\omega_{0}$ to $2 \omega_{0}$ is observed after the first beating as shown in Fig. 6c. The beating disappears as the damping increases (see Fig. 7). The maximum amplitude of both transient and steady state in-plane response of the cable at mid span are plotted as a function of the damping. Fig. 8a shows that the amplitude of both transient and steady state responses, and also the difference between them, decreases by increasing the damping in the cable. For high damping, the transient response disappears and the response goes directly to a steady state. The parametric resonance also disappears when the damping achieve a critical value of damping ( $\xi=1.19 \%$ in this case). Note that this critical value depends also on the amplitude of excitation. The time needed to trigger parametric resonance is also plotted as a function of the damping (Fig. 8b). Here we can see that parametric resonance triggers faster when the damping is small. And for high values of damping it needs a very long time to occur which means its disappearance.
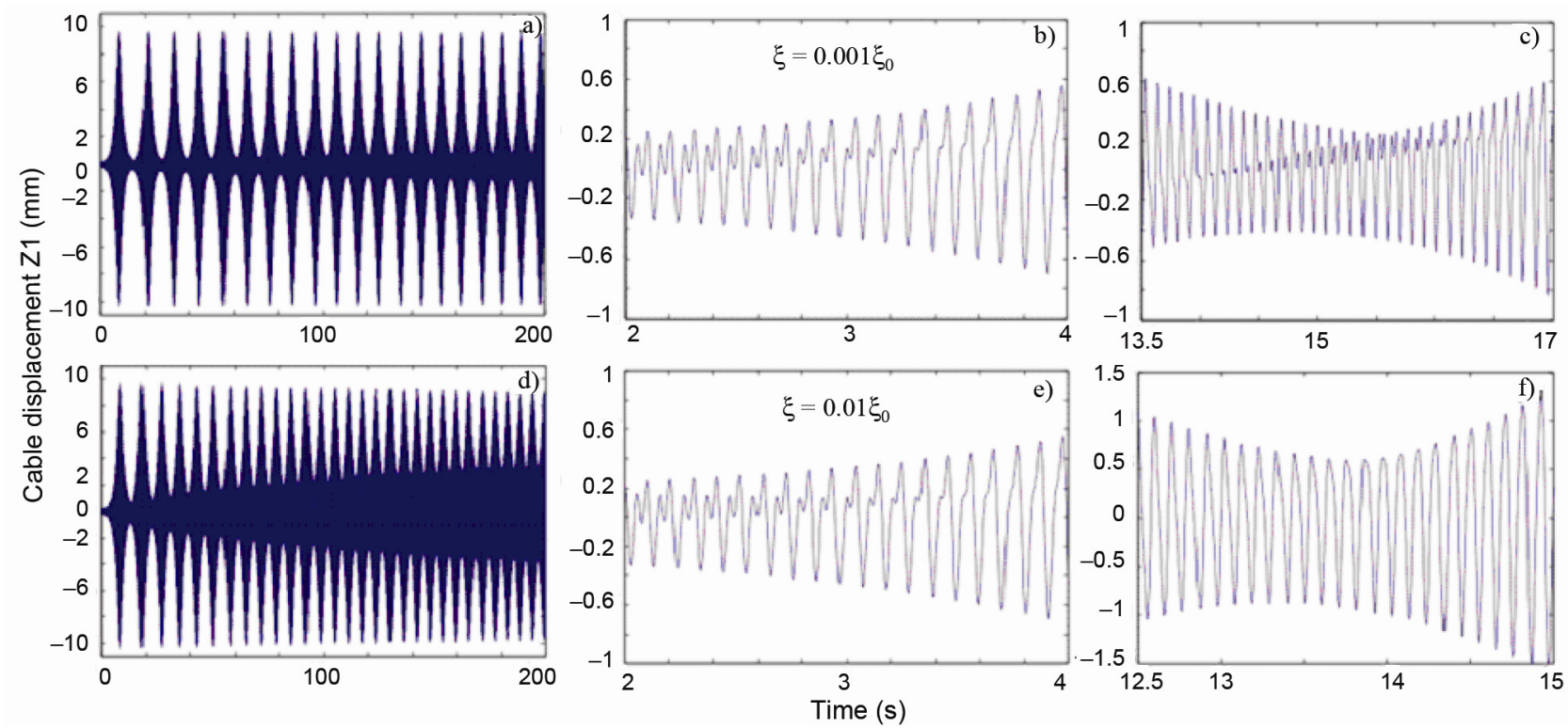

Fig. 6. Evolution in time of the cable mid span displacement under first order parametric excitation: (a), (b) and (c) - when $\xi=0.001 \xi_{0} ;(\mathrm{d}),(\mathrm{e})$ and (f) - when $\xi=0.01 \xi_{0} ;(\mathrm{b})$ and (e) zoom between $2 \mathrm{~s}$ and $4 \mathrm{~s}$; (c) zoom between $13.5 \mathrm{~s}$ and $17 \mathrm{~s} ;$ (f) zoom between $12.5 \mathrm{~s}$ and $15 \mathrm{~s}$ 

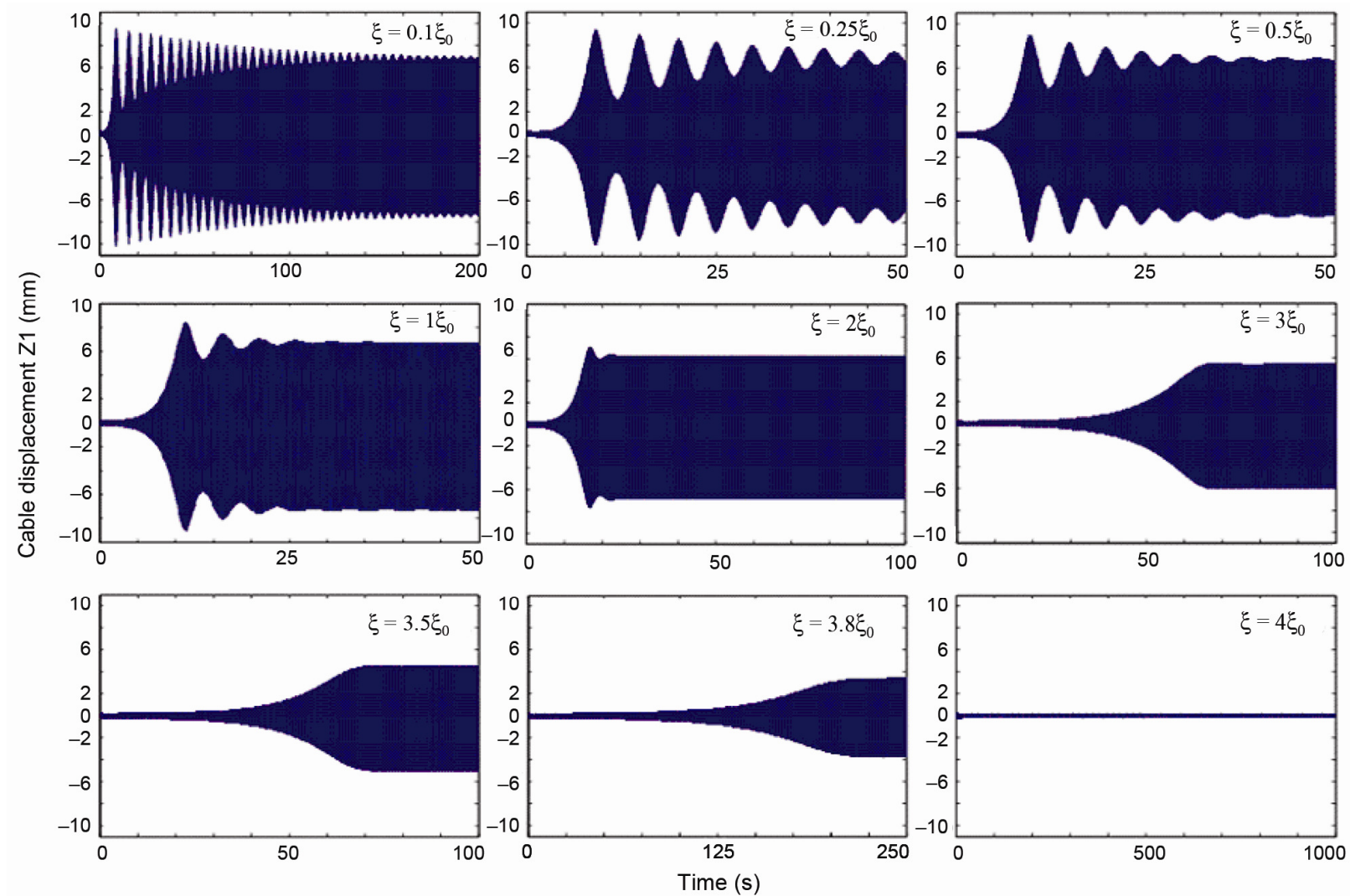

Fig. 7. Evolution in time of the in-plane cable mid span displacement under first order parametric excitation for different values of natural damping

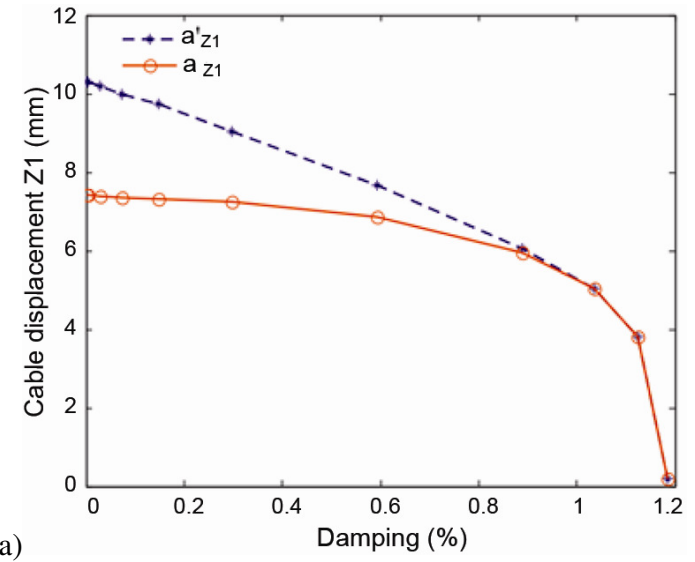

a)

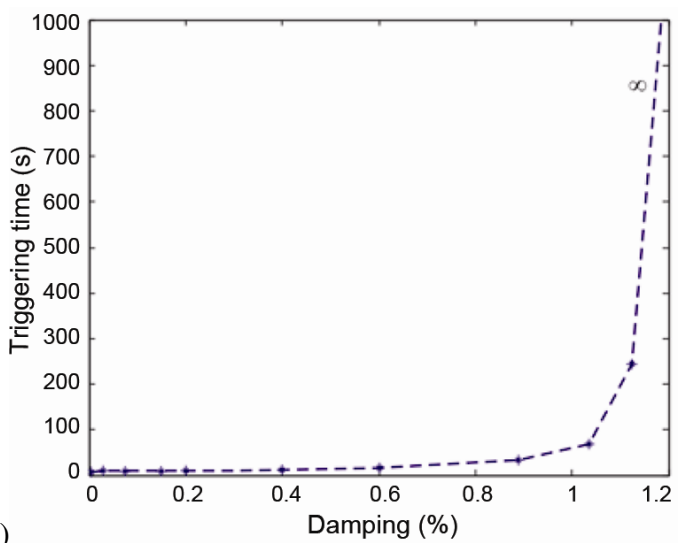

Fig. 8. Maximum mid span cable displacement (a); necessary time to trigger first order parametric resonance, as a function of the natural damping (b)

\subsection{Second order parametric excitation}

The same numerical experiences described in section 3.1 are reproduced for $k=2$, which corresponds to a frequency of excitation equal to the fundamental frequency of the cable. Investigating the dynamic response of the cable under this particular frequency of excitation, allows studying the second order parametric excitation. The time evolution of the mid span vertical displacement (Z1) is plotted for this case in Fig. 9a. Large vertical oscillations of the cable at mid span are also observed but without any change of the cable vibration frequency (Fig. 9b).

By changing the frequency of excitation near the initial frequency of excitation $\left(\omega_{0}\right)$ and plotting in Fig. 10a the maximum amplitude of both transient $\left(a_{Z 1}^{\prime}\right)$ and steady state $\left(a_{Z 1}\right)$ in-plane response of the cable at mid span as a function of the frequency of excitation, one can see that the shape of the frequency-response curve is similar to that of a single-d.o.f. model under primary external resonance (Berlioz, Lamarque 2005). The parametric resonance occurs in a frequency band larger than for the case of first order parametric excitation. This means that the risk of producing a second order parametric resonance is higher than for a first order parametric excitation.

The transient in-plane response appears for all frequencies near the first cable frequency whereas for the case of first order parametric excitation the transient response disappears for frequencies close to $\omega_{\min }$. 


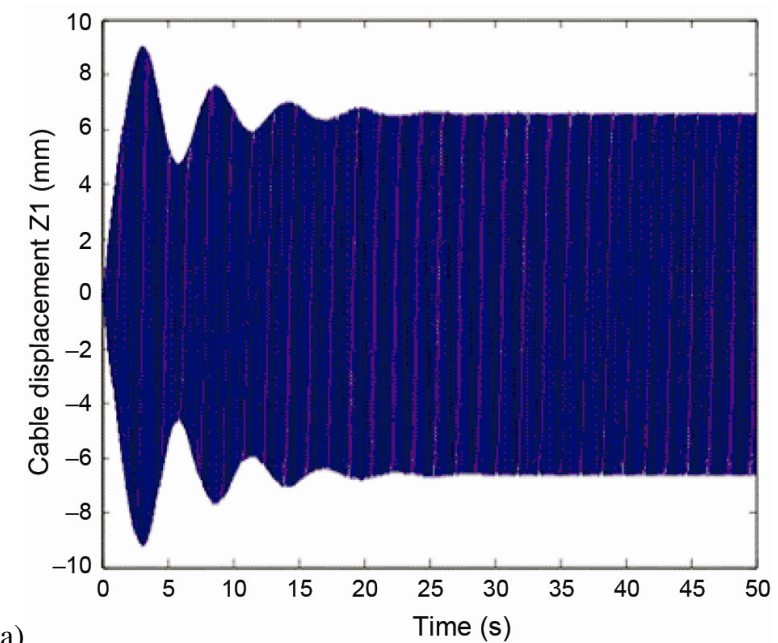

a)

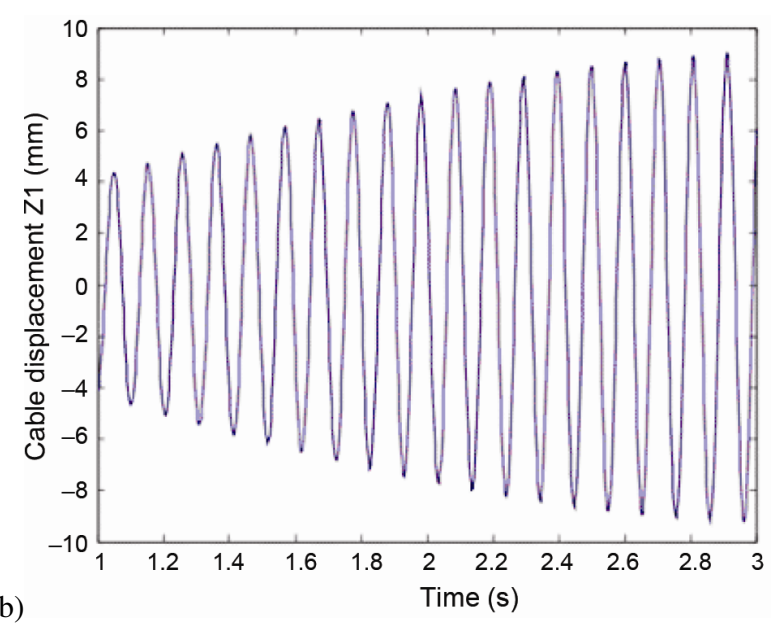

Fig. 9. In-plane cable vibration at mid span under second order parametric excitation as a function of time (a); zoom between $1 \mathrm{~s}$ and $3 \mathrm{~s} \mathrm{(b)}$

The necessary time to trigger parametric resonance is also plotted as a function of the frequency of excitation (Fig. 10b). Second order parametric resonance triggers slower when the frequency of excitation is very close to $\omega_{0}$ but triggers faster when frequency changes around $\omega_{0}$. The second order parametric resonance triggers faster than the first parametric excitation.

Next, the effect of the amplitude of excitation on the second order parametric resonance is studied. The maximum mid span cable displacements are plotted as a function of the amplitudes of excitation and compared to those obtained from first order parametric excitation (Fig. 11a). This figure reveals that the second order parametric excitation doesn't need threshold amplitude to trigger and that the maximum response increases by increasing the amplitude of excitation. The second order parametric excitation produces a maximum in-plane displacement Z1 larger than the one under first order excitation up to an amplitude of excitation equal to $0.08 \mathrm{~mm}$. Beyond this value, the first order parametric excitation produces the largest oscillations of the cable at mid span. Fig. 11b shows that the time needed to trigger a second order parametric resonance is faster than the first order parametric resonance.
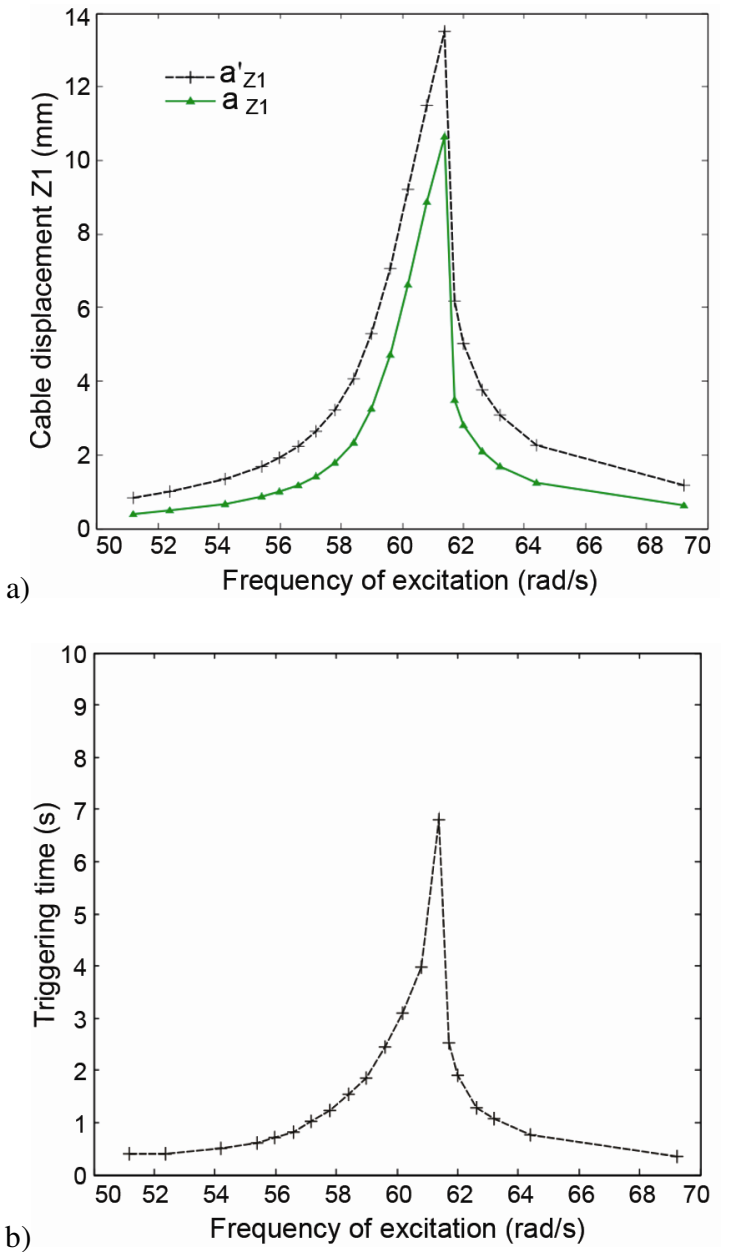

Fig. 10. Maximum mid span cable displacement (a); necessary time to trigger second order parametric resonance as a function of the frequency of excitation (b)

Finally, the effect of natural damping on the second order parametric resonance is investigated. The amplitude and the frequency of excitation are fixed respectively to $a_{u}=0.1 \mathrm{~mm}$ and $\omega_{\text {excit }}=\omega_{0}$. The natural damping ( $\xi_{0}=0.3 \%$ ) of the cable is changed from small to high values. The maximum amplitude of both transient and steady state in-plane response of the cable at mid span are plotted as a function of the damping. Fig. 12a shows that the cable vibration induced by second order parametric excitation needs higher values of damping ratio to be reduced, unlike the first order parametric excitation. The damping has no significant effect on the time needed to trigger a second order parametric resonance as shown in Fig. 12b.

\section{Conclusions}

A nonlinear model of a cable with small sag and support movement is used to investigate the nonlinear oscillations of a single-d.o.f. planar cable under first and second order parametric excitations. Maximum amplitudes of the inplane transient and steady state cable responses at its mid span are examined as a function of amplitude and frequency of excitation as well as natural damping of the cable. It had been shown that the existence of parametric 


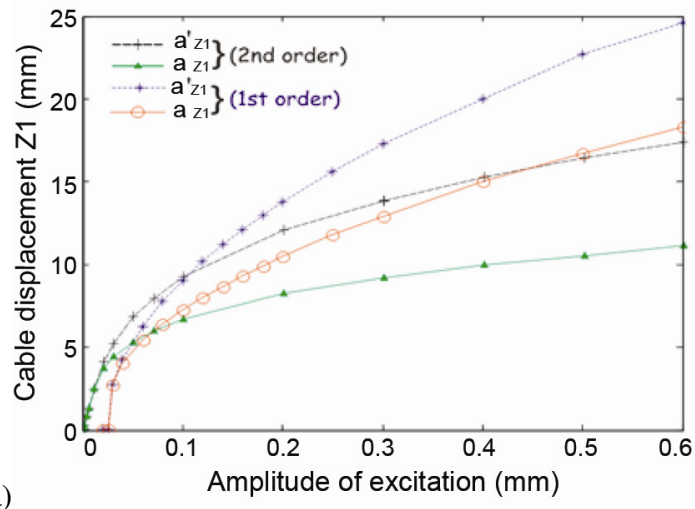

a)

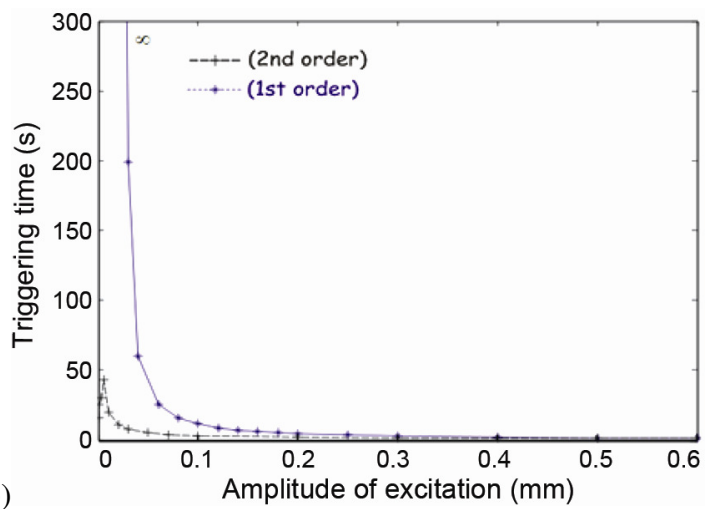

b)

Fig. 11. Maximum mid span cable displacements (a); necessary time to trigger parametric resonance; as a function of the amplitude of excitation (b)

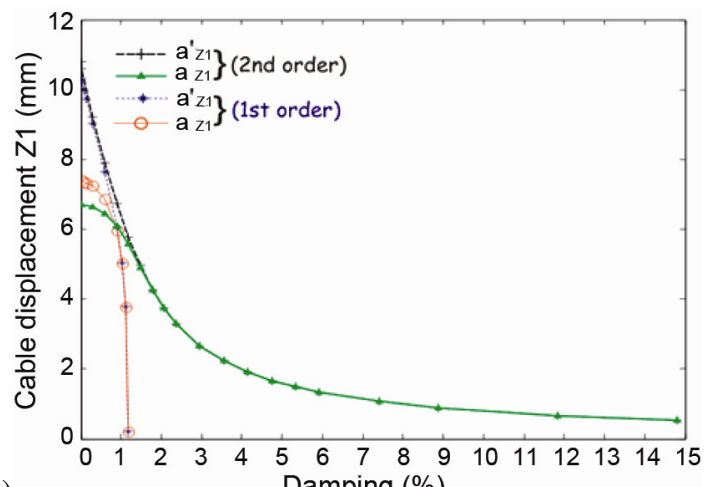

a)

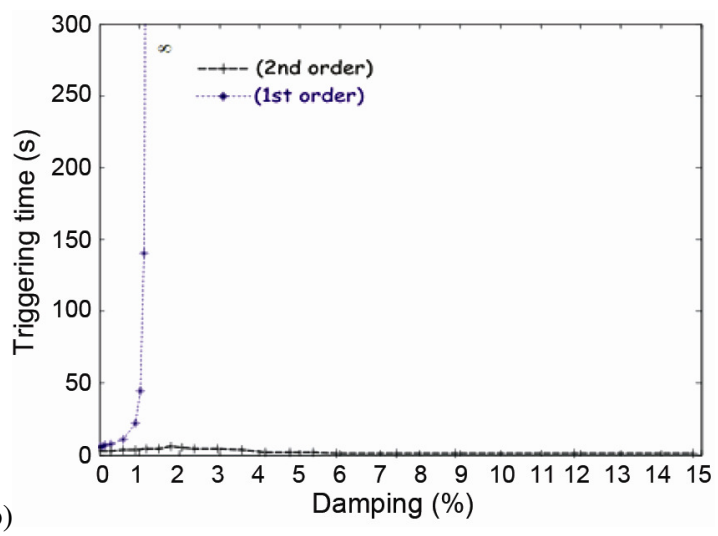

Fig. 12. Maximum mid span cable displacements (a); necessary time to trigger parametric resonance, as a function of the natural damping (b) excitation depends on these three parameters. The first order parametric resonance triggers faster as the amplitude of excitation increases, the natural damping decreases and the frequency of excitation is exactly twice that of the fundamental frequency of the cable. The second order parametric resonance is more difficult to damp and triggers faster than the first order one for any amplitude of excitation.

\section{References}

Benedettini, F.; Rega, G.; Alaggio, R. 1995. Non-linear oscillations of a four-degree-of-freedom model of a suspended cable under multiple internal resonance conditions, Journal of Sound and Vibration 182(5): 775-798. http://dx.doi.org/10.1006/jsvi.1995.0232

Berlioz, A.; Lamarque, C.-H. 2005. A non-linear model for the dynamics of an inclined cable, Journal of Sound and Vibration 279(3-5): 619-639. http://dx.doi.org/10.1016/j.jsv.2003.11.069

Bossens, F. 2001. Amortissement actif des structures câblées: de la théorie à l'implémentation [Active damping of cable structures: from theory to implementation]. $\mathrm{PhD}$ thesis. Belgium: Free University of Brussels.

Chen, H.; Xu, Q. 2009. Bifurcations and chaos of an inclined cable, Nonlinear Dynamics 57(1-2): 37-55. http://dx.doi.org/10.1007/s11071-008-9418-3

Hagedorn, P.; Schäfer, B. 1980. On nonlinear free vibrations of an elastic cable, International Journal of Non-Linear Mechanics 15(4-5): 333-340. http://dx.doi.org/10.1016/0020-7462(80)90018-9

Hu, J.; Frank Pai, P. 2010. Experimental study of the nonlinear dynamic characteristics of suspended taut steel cables using a 3-D motion analysis system, Journal of Sound and Vibration 329(19): 3972-3998. http://dx.doi.org/10.1016/j.jsv.2010.04.006

Ibrahim, R. A. 2004. Nonlinear vibrations of suspended cables, Part III: Random excitation and interaction with fluid flow, Applied Mechanics Reviews 57(6): 515-549. http://dx.doi.org/10.1115/1.1804541

Irvine, M. 1992. Cable Structures. New York: Dover Publications. 259 p.

Irvine, M.; Caughey, T. K. 1974. The linear theory of free vibrations of a suspended cable, in Proc. of Royal Society of London, December, 1974, Vol. 341, No 1626, 299-315. http://dx.doi.org/10.1098/rspa.1974.0189

Juozapaitis, A.; Norkus, A. 2004. Displacement analysis of asymmetrically loaded cable, Journal of Civil Engineering and Management 10(4): 277-284.

http://dx.doi.org/10.1080/13923730.2004.9636320

Kahla, N. B. 1995. Dynamics of a single guy cable, Computers and Structures 54(6): 1197-1211. http://dx.doi.org/10.1016/0045-7949(94)00391-F

Lacarbonara, W.; Pacitti, A. 2008. Nonlinear modeling of cables with flexural stiffness, Mathematical Problems in Engineering Vol. 2008, ID 370767.

Lilien, J. L.; Pinto da Costa, A. 1994. Vibration amplitudes caused by parametric excitation of cable stayed structures, Journal of Sound and Vibration 174(1): 69-90. http://dx.doi.org/10.1006/jsvi.1994.1261

Nayfeh, S. A.; Nayfeh, A. H.; Mook, D. T. 1995. Nonlinear response of a taut string to longitudinal and transverse end excitation, Journal of Vibration and Control 1(3): 307334. http://dx.doi.org/10.1177/107754639500100304 
Ni, Y. Q.; Ko, J. M.; Zheng, G. 2002. Dynamic analysis of large-diameter sagged cables taking into account flexural rigidity, Journal of Sound and Vibration 257(2): 301-319. http://dx.doi.org/10.1006/jsvi.2002.5060

Nielsen, S. R. K.; Sichani, M. T. 2011. Stochastic and chaotic sub- and superharmonic response of shallow cables due to chord elongations, Probabilistic Engineering Mechanics 26(1): 44-53.

http://dx.doi.org/10.1016/j.probengmech.2010.06.006

Perkins, N. C. 1992. Modal interaction in the non-linear response of elastic cables under parametric/external excitation, International Journal of Non-Linear Mechanics 27(2): 233-250.

http://dx.doi.org/10.1016/0020-7462(92)90083-J

Rega, G. 2004a. Nonlinear vibrations of suspended cables - Part I: Modeling and analysis, Applied Mechanics Reviews 57(6): 443-478. http://dx.doi.org/10.1115/1.1777224

Rega, G. 2004b. Nonlinear vibrations of suspended cables - Part II: Deterministic phenomena, Applied Mechanics Reviews 57(6): 479-514. http://dx.doi.org/10.1115/1.1777225

Rega, G.; Benedettini, F. 1989. Planar non-linear oscillations of elastic cables under subharmonic resonance conditions, Journal of Sound and Vibration 132(3): 367-381. http://dx.doi.org/10.1016/0022-460X(89)90631-7

Rega, G.; Srinil, N. and Alaggio, R. 2008. Experimental and numerical studies of inclined cables: free and parametrically-forced vibrations. Journal of Theoretical and Applied Mechanics, 46(3): 621-640.

Ren, W.-X.; Chen, G.; Hu, W.-H. 2005. Empirical formulas to estimate cable tension by cable fundamental frequency, Structural Engineering and Mechanics 20(3): 363-380.

Sousa, R. A.; Souza, R. M.; Figueiredo, F. P.; Menezes, I. F. M. 2011. The influence of bending and shear stiffness and rotational inertia in vibrations of cables: An analytical approach, Engineering Structures 33(3): 689-695. http://dx.doi.org/10.1016/j.engstruct.2010.11.026

Srinil, N.; Rega, G. 2007. The effects of kinematic condensation on internally resonant forced vibrations of shallow horizontal cables, International Journal of Non-Linear Mechanics 42(1): 180-195.

http://dx.doi.org/10.1016/j.ijnonlinmec.2006.09.005

Starossek, U. 1994. Cable dynamics: A review, Structural Engineering International (3): 171-176.

Sun, B. N.; Wang, Z. G.; Ko, J. M.; Ni, Y. Q. 2003. Parametrically excited oscillation of stay cable and its control in cablestayed bridges, Journal of Zhejiang University of Science 4(1): 13-20. http://dx.doi.org/10.1631/jzus.2003.0013

Takahashi, K. 1991. Dynamic stability of cables subjected to an axial periodic load, Journal of Sound and Vibration 144(2): 323-330. http://dx.doi.org/10.1016/0022-460X(91)90752-6

Takahashi, K.; Chen, B. 2006. Influence of cable loosening on nonlinear parametric vibrations of inclined cables, Structural Engineering and Mechanics 25(2): 219-237.

Takahashi, K.; Konishi, Y. 1987. Non-linear vibrations of cables in three dimensions, part II: Out-of-plane vibrations under in-plane sinusoidally time-varying load, Journal of Sound and Vibration 118(1): 85-97. http://dx.doi.org/10.1016/0022-460X(87)90256-2

Treyssède, F. 2010. Vibration analysis of horizontal selfweighted beams and cables with bending stiffness subjected to thermal loads, Journal of Sound and Vibration 329(9): 1536-1552.

http://dx.doi.org/10.1016/j.jsv.2009.11.018
Triantafyllou, M. S. 1984. Linear dynamics of cables and chains, The Shock and Vibration Digest 16(3): 9-17. http://dx.doi.org/10.1177/058310248401600305

Triantafyllou, M. S. 1987. Dynamics of cables and chains, The Shock and Vibration Digest 19(12): 3-5. http://dx.doi.org/10.1177/058310248701901202

Triantafyllou, M. S. 1991. Dynamics of cables, towing cables and mooring systems, The Shock and Vibration Digest 23(7): 3-8. http://dx.doi.org/10.1177/058310249102300703

Wang, L.; Rega, G. 2010. Modelling and transient planar dynamics of suspended cables with moving mass, International Journal of Solids and Structures 47(20): 27332744. http://dx.doi.org/10.1016/j.ijsolstr.2010.06.002

Wang, L.; Zhao, Y. 2009a. Large amplitude motion mechanism and non-planar vibration Character of stay cables subject to the support motions, Journal of Sound and Vibration 327(1-2): 121-133. http://dx.doi.org/10.1016/j.jsv.2009.06.013

Wang, L.; Zhao, Y. 2009b. Multiple internal resonances and non-planar dynamics of shallow suspended cables to the harmonic excitations, Journal of Sound and Vibration 319 (1-2): 1-14. http://dx.doi.org/10.1016/j.jsv.2008.08.020

Wu, Q.; Takahashi, K.; Nakamura, S. 2005. Formulae for frequencies and modes of in-plane vibrations of small-sag inclined cables, Journal of Sound and Vibration 279(3-5): 1155-1169. http://dx.doi.org/10.1016/j.jsv.2004.01.004

Wu, Q.; Takahashi, K.; Okabayashi, T.; Nakamura, S. 2003. Response characteristics of local vibrations in stay cables on an existing cable-stayed bridge, Journal of Sound and Vibration 261(3): 403-420.

http://dx.doi.org/10.1016/S0022-460X(02)01088-X

\section{Appendix}

The Irvine's parameter (Irvine 1992) involving cable elasticity and geometry is defined by:

$$
\lambda^{2}=\left(\frac{\rho g l \cos \theta}{\sigma^{s}}\right)^{2} \frac{E}{\sigma^{s}},
$$

where $E$ is the cable modulus of elasticity.

The effective modulus of elasticity is defined as:

$$
E_{q}=\frac{1}{1+\frac{\lambda^{2}}{12}} E .
$$

The kinetic energy of the cable is:

$$
\begin{gathered}
K_{c}=\frac{1}{2} \rho A l\left\{\left(\frac{1}{1+\frac{\lambda^{2}}{12}}\right)^{2}\left(\frac{1}{3}+\frac{\lambda^{2}}{18}+\frac{\lambda^{4}}{432}+\frac{\lambda^{2}}{120} \frac{E}{\sigma^{s}}\right)\left(\dot{u}_{b}-\dot{u}_{a}\right)^{2}+\right. \\
\dot{u}_{b} \dot{u}_{a}+\frac{1}{3}\left(\dot{v}_{b}-\dot{v}_{a}\right)^{2}+\dot{v}_{b} \dot{v}_{a}+\frac{1}{3}\left(\dot{w}_{b}-\dot{w}_{a}\right)^{2}+\dot{w}_{b} \dot{w}_{a}- \\
\frac{1}{12} \frac{1}{1+\frac{\lambda^{2}}{12}} \sqrt{\frac{\sigma^{s}}{E}}\left[1+\frac{\lambda^{2}}{12}+\frac{E}{\sigma^{s}}\right]\left(\dot{w}_{b}-\dot{w}_{a}\right)\left(\dot{u}_{b}-\dot{u}_{a}\right)+ \\
\frac{\lambda^{2}}{120} \frac{E}{\sigma^{s}}\left(\dot{w}_{b}-\dot{w}_{a}\right)^{2}-\frac{1}{6} \frac{1}{1+\frac{\lambda^{2}}{12}} \sqrt{\frac{\sigma^{s}}{E}}\left(\dot{u}_{b}-\dot{u}_{a}\right) \dot{w}_{a}-
\end{gathered}
$$




$$
\begin{gathered}
\frac{\lambda}{6} \sqrt{\frac{\sigma^{s}}{E}}\left(\dot{w}_{b}-\dot{w}_{a}\right) \quad \dot{u}_{a}+\sum_{n}\left[\frac{2}{n \pi}\left(\dot{v}_{a}+(-1)^{n+1} \dot{v}_{b}\right) \dot{y}_{n}-\right. \\
2 \frac{\gamma \quad l}{\sigma^{s}} \frac{\left(1+(-1)^{n+1}\right)}{n \pi} \frac{1}{(n \pi)^{2}} \frac{E_{q}}{\sigma^{s}}\left(\dot{u}_{b}-\dot{u}_{a}\right) \dot{z}_{n}+ \\
\left.\left.\frac{1}{2} \dot{y}_{n}^{2}+\frac{1}{2} \dot{z}_{n}^{2}+\frac{2}{n \pi}\left(\dot{w}_{a}+(-1)^{n+1} \dot{w}_{b}\right) \dot{z}_{n}\right]\right\} .
\end{gathered}
$$

In our case, the strain energy can be written as:

$$
\begin{gathered}
\varepsilon(x, t)=\varepsilon_{x x}(x, t)=\frac{\partial u^{q}}{\partial x}+\frac{1}{2}\left[\left(\frac{\partial u^{q}}{\partial x}\right)^{2}+\right. \\
\left.\left(\frac{\partial\left(v^{q}+v^{d}\right)}{\partial x}\right)^{2}+\left(\frac{\partial\left(w^{s}+w^{q}+w^{d}\right)}{\partial x}\right)^{2}\right] .
\end{gathered}
$$

Since we assume that the strain (tension) is constant along the cable span, the dynamical strain is a function of time only; averaging $(x, t)$ over the cable span, we get:

$$
\begin{gathered}
\bar{\varepsilon}(t)=\frac{1}{l} \int_{0}^{l} \varepsilon(x, t) d x ; \\
\bar{\varepsilon}(t)=\frac{T_{0}}{E A}+\frac{E_{q}}{E} \frac{u_{b}-u_{a}}{l}+\frac{\gamma}{T_{0}} \sum_{n}\left[\frac{z_{n}(t)}{n \pi}\left(1+(-1)^{n+1}\right)\right]+ \\
\frac{1}{2} \sum_{n}\left(y_{n}(t)^{2} \frac{n^{2} \pi^{2}}{2 l^{2}}\right)+\frac{1}{2} \sum_{n}\left(z_{n}(t)^{2} \frac{n^{2} \pi^{2}}{2 l^{2}}\right)+ \\
\frac{E_{q} A^{2} \gamma}{T_{0}^{2}} \frac{u_{b}-u_{a}}{l} \sum_{n} \frac{z_{n}(t)\left((-1)^{n}-1\right)}{n \pi}+ \\
\frac{\left(u_{b}-u_{a}\right)^{2}}{2 l^{2}}\left[1+\frac{E_{q}}{\sigma^{s}} \frac{\lambda^{2}}{12+\lambda^{2}}\right]+\frac{\left(v_{b}-v_{a}\right)^{2}}{2 l^{2}}+ \\
\frac{\left(w_{b}-w_{a}\right)^{2}}{2 l^{2}}\left[1+\frac{\lambda^{2} \sigma^{s}}{12 E}\right] .
\end{gathered}
$$
cable is:

So the strain energy due to elastic elongation of the

$$
U_{c, d}=\frac{E A}{2} \int_{0}^{l} \varepsilon(x, t)^{2} d x=\frac{E A l}{2} \bar{\varepsilon}(t)^{2} .
$$

The gravitational potential energy is:

$$
\begin{gathered}
U_{c, g}=\rho A g l \int_{0}^{l}\left[-\left(w^{s}+w^{q}+w^{d}\right) \cos \theta+u^{q} \sin \theta\right] d x= \\
-\rho g A \cos \theta \frac{\gamma l^{3}}{12 \sigma^{s}}+\frac{1}{2} \rho A g l \sin \theta\left(u_{b}+u_{a}\right)+ \\
\frac{1}{12} \frac{\rho A^{3} g E_{q} \gamma l^{2} \cos \theta}{T_{0}^{2}}\left(u_{b}-u_{a}\right)- \\
\frac{1}{12} \frac{\rho \operatorname{lo} A^{2} g \quad \gamma \quad l^{2} \sin \theta}{T_{0}}\left(w_{b}-w_{a}\right) \\
-\rho A \quad g \quad l \cos \theta \sum_{n} \frac{\left(1+(-1)^{n+1}\right)}{n \pi} z_{n} .
\end{gathered}
$$

The Total potential energy is:

$$
U=U_{c, g}+U_{c, d} \text {. }
$$

Mohamed Hechmi EL OUNI. Teaching Assistant at the Dept of Mechanical Engineering of the Higher Institute of Applied Sciences and Technologies of Sousse, University of Sousse Tunisia. He is currently a PhD student at the Dept of Civil Engineering of the National School of Engineering of Tunis (ENIT), Tunisia, from which he obtained a Master of Science in soil, structures and materials. He is a member of the Laboratory of Systems and Applied Mechanics, Polytechnic School of Tunisia, La Marsa, Tunisia. Research interests: Cable dynamics, non-linear static and dynamic analysis of cable structures, tensegrity structures, active control of flexible structures.

Nabil BEN KAHLA. The dean of the Higher Institute of Applied Sciences and Technologies of Sousse, University of Sousse Tunisia. He is an Assoc. Prof. at the Dept of Mechanical Engineering. He obtained his PhD degree from the University of Wisconsin-Madison, USA. He is a member of the Laboratory of Systems and Applied Mechanics, Polytechnic School of Tunisia, La Marsa, Tunisia. He is the author of several scientific papers. Research interests: non-linear cable dynamics, guyed masts, tensegrity structures, discrete element methods, active and passive control of flexible structures. 